\title{
Condiciones determinantes para la producción del conocimiento y la investigación en Jalisco
}

DOI: https://doi.org/10.32870/dse.v0i12.267

\section{Mitchell Alberto Alarcón Díaz*}

\section{Reseña}

Vergara, Martha y Aurora Ojeda (2014). La producción del conocimiento en las instituciones educativas de Jalisco. Guadalajara: Universidad de Guadalajara, 189 pp.

Las instituciones educativas son un espacio para la creación, producción y promoción del saber por excelencia. En ese escenario, estas instituciones y los sujetos que conviven en ella ponen en práctica una serie de enfoques, métodos y diseños de investigación que posteriormente los conducen hacia nuevos saberes que iluminarán la práctica de futuras intenciones investigativas.

El texto La producción del conocimiento en las instituciones educativas de Jalisco es un esfuerzo intelectual en conjunto que nos permite aproximarnos al entendimiento de la dinámica bajo la cual se desarrolla la producción, organización, los factores condicionantes, la gestión y la difusión del conocimiento en las instituciones educativas del estado de Jalisco.

Cada capítulo de este libro contribuye a la construcción de una comunidad académica más sensible, esto a través del conocimiento de las fortalezas y debilidades que subyacen al interior de las instituciones vinculadas al campo educativo.

Esta publicación ha sido presentada en seis apartados que fueron escritos por nueve investigadores de reconocida trayectoria académica e intelectual, lo que demuestra la preocupación constante por el desarrollo de la investigación al interior de los espacios educativos mexicanos. Cada uno de los capítulos propuestos guarda una relación en torno a la búsqueda de nuevas respuestas ante las interrogantes actuales referidas a la educación contemporánea.

En el apartado titulado "La institución como espacio privilegiado en la producción de conocimiento”, Martha Vergara Fregoso nos presenta un valioso aporte a la identificación, descripción y análisis de los procesos de investigación. La razón de ser de una institución vinculada al quehacer educativo es la de generar espacios de conocimiento y, muchas veces, la heterogeneidad de estas instituciones se convierte en una valiosa oportunidad de desarrollo pero, para que ello suceda, ten-

* Doctorado en Ciencias de la educación por la Universidad Nacional de Educación Enrique Guzmán y Valle (Perú). Posdoctorado en Sistemas diacrónicos y sincrónicos de la investigación científica. Correo electrónico: vapalarcon@hotmail.com. 
drían que existir una serie de condiciones que favorezcan la evolución de la investigación como proceso. Así, mediante un proceso de sistematización de la información se analizó el desarrollo de la praxis investigativa. La visión panorámica de la realidad que la autora presenta podría llegar a identificar premisas valiosas para enriquecer la investigación y así incrementar la calidad del proceso de enseñanza aprendizaje del estudiantado.

Por su parte, Aurora Ojeda Alva nos ofrece un interesante análisis sobre la organización de la producción del conocimiento. En este estudio se exploran un conjunto de instituciones y se focaliza la atención en aspectos tales como la producción de conocimiento a partir de la relación sujeto institución así como la consideración de la producción de conocimiento como un proceso dinámico, social y consecuentemente, complejo. La reflexión acerca de la necesidad institucional de crear modelos de sistematización y de gestión de información se constituye en fundamental ya que éste podría ser uno de los pilares para aproximar a la institución hacia modelos productivos de conocimiento emergente.

También es sumamente significativa la contribución de Elvira Fuentes Márquez y Cristina Aparicio Ávila quienes, a partir de un escrito relacionado con las condiciones institucionales de la gestión y la producción del conocimiento, nos presentan un diagnóstico acerca de las líneas de investigación como una forma de orientar el camino del investigador y también grafican aquellas condiciones con las que conviven los sujetos al momento de encaminar una intención investigativa. La reflexión a la que nos conducen las autoras se constituye en un discurso de enorme valía ya que desnuda aquellas fortalezas pero también las tensiones existentes al interior de las instituciones educativas y que se ponen de manifiesto durante el acto investigativo.

El trabajo relacionado con la gestión de la producción del conocimiento presentado por Armando Martín Ibarra López es una descripción y a la vez una reflexión acerca de las particularidades referidas a la organización, administración y las formas de operar la producción de conocimiento. A través de su discurso el autor identifica una serie de vacíos que obstaculizan el avance de la ciencia al interior de las instituciones. En ellas las personas adquieren un papel activo y central. Comprender el fenómeno científico y generar propuestas para su desarrollo son algunos considerandos abordados por Ibarra López.

Asimismo, la investigadora Nimia Ruth Flores Santillán nos comparte el artículo relacionado con la difusión y la diseminación de la investigación en las instituciones de Jalisco. Este trabajo grafica de manera documental el desarrollo que describe la espiral del conocimiento y refleja el impacto que tienen los espacios virtuales al momento de la divulgación de las investigaciones. También nos hace reflexionar acerca de la necesidad de diversificar las formas de divulgación científica con el fin de generar nuevos espacios de saber.

El trabajo de Juanita Correa Reyes, Raquel Domínguez Mora y Candelario Fernández Agráz, basado en el análisis desde la investigación educativa en su micro y macro entorno, nos conduce a un denso pero objetivo análisis y descripción de los diferentes procesos de vinculación de las 
instituciones educativas de Jalisco. A través de una serie de indicadores se caracterizan una serie de convenios y programas mediante los cuales se interrelacionan estas instituciones. Aparte de considerar una visión de permanente dialogo interinstitucional, responsable y reciproco, también las autoras coinciden en la necesidad de proponer planes estratégicos que apuntalen el factor investigación al interior de las instituciones.

Un elemento muy especial en esta publicación lo constituye la participación de Martha Vergara Fregoso y de Aurora Ojeda Alva, quienes en su rol de coordinadoras lideraron este esfuerzo en conjunto, que se convirtió en una evidencia real y concreta de que existen caminos viables, oportunos y dinámicos para construir una comunidad académica más vigorosa, mejor integrada y cada vez más consciente de lo que acontece al interior de las instituciones de educación.

Finalmente, la valía de las propuestas temáticas enlazadas a lo largo de cada uno de los capítulos contenidos en esta publicación nos ofrece una oportunidad para dirigir nuestra mirada hacia las instituciones y a los sujetos que concretan el quehacer investigativo en los espacios educativos del estado de Jalisco. 